\title{
INHALATION TOXICITY OF BREVETOXIN 3 IN RATS EXPOSED FOR FIVE DAYS
}

\author{
Janet M. Benson ${ }^{1}$, Fletcher F. Hahn ${ }^{1}$, Thomas H. March ${ }^{1}$, Jacob D. McDonald ${ }^{1}$, Mohan L. \\ Sopori ${ }^{1}$, JeanClare Seagrave ${ }^{1}$, Andrea P. Gomez ${ }^{1}$, Andrea J. Bourdelais ${ }^{2}$, Jerome Naar ${ }^{2}$, \\ Julia Zaias ${ }^{3}$, Gregory D. Bossart ${ }^{4}$, and Daniel G. Baden ${ }^{2}$ \\ ${ }^{1}$ Lovelace Respiratory Research Institute, 2425 Ridgecrest Dr. SE, Albuquerque, NM 87108 \\ ${ }^{2}$ Center for Marine Science Research, University of North Carolina at Wilmington, 5600 Marvin K. \\ Moss Lane, Wilmington, NC 28409 \\ ${ }^{3}$ University of Miami, Dept. of Pathology, Miami, FL 33136 \\ ${ }^{4}$ Division of Marine Mammal Research and Conservation, Harbor Branch Oceanographic Institution, \\ Ft. Pierce, FL 34946
}

\begin{abstract}
Brevetoxins are potent neurotoxins produced by the marine dinoflagellate, Karenia brevis. Exposure to brevetoxins may occur during a $K$. brevis red tide when the compounds become aerosolized by wind and surf. This study assesses possible adverse health effects associated with short-term inhalation exposure to brevetoxin 3. Male Sprague-Dawley rats were exposed to $500 \mu \mathrm{g}$ brevetoxin $3 / \mathrm{m}^{3}$ by nose-only inhalation for 0.5 or $2 \mathrm{hr} / \mathrm{day}$ for 5 consecutive days. Control rats were sham exposed for $2 \mathrm{hr}$ to vehicle. Calculated deposited brevetoxin doses were 8.3 and $33 \mu \mathrm{g} / \mathrm{kg} / \mathrm{day}$ for the low- and high-dose groups, respectively. At the termination of exposures, only body weights of the high-dose group (Group B) were significantly below control values. By immunohistochemistry (IHC), small numbers of splenic and peribronchiolar lymphoid tissue macrophages stained positive for brevetoxin, while nasal mucosa, liver, and brain were IHC negative for brevetoxin. No gross or microscopic lesions were observed in any tissue examined. There was no biochemical evidence of cytotoxicity or inflammation in bronchoalveolar lavage fluid. Alveolar macrophages showed some evidence of activation following brevetoxin exposure. Humoral-mediated immunity was suppressed
\end{abstract}

$\begin{array}{lccl}\text { Author } & \text { Phone } & \text { Fax } & \text { e-mail } \\ \text { Janet M. Benson } & 505-348-9457 & 505-348-4980 & \text { jbenson@1rri.org } \\ \text { Fletcher F. Hahn } & 505-348-9428 & 505-348-8567 & \text { fhahn@1rri.org } \\ \text { Thomas H. March } & 505-348-9482 & 505-348-8567 & \text { tmarch@1rri.org } \\ \text { Jacob D. McDonald } & 505-348-9455 & 505-348-4980 & \text { jmcdonal@1rri.org } \\ \text { Mohan L. Sopori } & 505-348-9440 & 505-348-8567 & \text { msopori@1rri.org } \\ \text { JeanClare Seagrave } & 505-348-9499 & 505-348-8567 & \text { jseagrav@1rri.org } \\ \text { Andrea P. Gomez } & 505-348-9560 & 505-348-4980 & \text { agomez@1rri.org } \\ \text { Andrea J. Bourdelais } & 910-962-2365 & 910-962-2410 & \text { bourdelaisa@uncw.edu } \\ \text { Jerome Naar } & 910-962-2367 & 910-962-2410 & \text { naarj@uncw.edu } \\ \text { Julia Zaias } & 305-243-6700 & 303-242-5662 \text { ext 556 } & \text { jzaias@med.miami.edu } \\ \text { Gregory Bossart } & 772-465-2400 & 772-466-4853 & \text { gbossart@hboi.edu } \\ \text { Daniel G. Baden } & 910-062-2300 & 910-962-2143 & \text { badend@uncw.edu }\end{array}$


in brevetoxin-exposed rats as indicated by a 70\% reduction in splenic plaque forming cells in brevetoxin-exposed animals compared to controls. Results suggest that the immune system may be a target of toxicity following brevetoxin inhalation. Future studies will focus on identification of a no-effect level and mechanisms underlying brevetoxin-induced immune suppression.

\section{INTRODUCTION}

Blooms of the dinoflagellate, Karenia brevis, are responsible for what are commonly referred to as Florida red tides. K. brevis produces a series of cyclic polyethers, known as brevetoxins. These compounds bind with high affinity to Site 5 of voltage-gated sodium channels and are highly neurotoxic upon acute exposure (Baden, 1989). Brevetoxins are responsible for neurotoxic shellfish poisoning in people having eaten $K$. brevis-contaminated shellfish. People may be more commonly exposed to brevetoxins during a red tide when the compounds become aerosolized by wind and surf and subsequently blown onshore as a component of sea spray. Exposure to aerosolized brevetoxins results in almost immediate irritation of the eyes and respiratory tract. The mechanism(s) underlying these effects have not been completely delineated. In vitro studies with isolated canine tracheal muscle have indicted that brevetoxininduced bronchoconstriction is due, at least in part, to stimulation of axon sodium channels in smooth muscle, resulting in the release of acetylcholine at postganglionic parasympathetic efferent nerve endings (Asai et al, 1982). Recent studies of inhaled brevetoxins in sheep have implicated histamine release in mediating observed airway restriction (Abraham et al, 2003). Brevetoxin may also stimulate cough receptor reflex or sodium channels of afferent vagus nerve fibers (Asai et al, 1982). Recently, Backer and colleagues (2003) correlated the extent of respiratory tract symptoms experienced by individuals recreationally exposed to aerosolized brevetoxins during a K. brevis red tide and the brevetoxin concentration in the air. Significant increases in eye irritation, throat irritation, and cough and chest tightness were reported by individuals exposed to $<10$ to $36 \mathrm{ng}$ total brevetoxin $/ \mathrm{m}^{3}$ ), while significant increases in nasal congestion and wheezing were reported by individuals exposed to $20-93 \mathrm{ng}$ brevetoxin $/ \mathrm{m}^{3}$.

K. brevis red tides occur almost annually in the Gulf of Mexico and have increased in geographic distribution since the 1970s (Van Dolah, 2000), therefore increasing the possibility of repeated inhalation exposure for individuals working and living along affected beaches and waterways. Despite this, little is known about the possible systemic health effects associated with aerosolized brevetoxins beyond the obvious immediate irritation (Kirkpatrick et al., 2003). Bossart et al. (1998) reported respiratory tract inflammation and hemopathy in manatees dying during the 1996 red tide events. While these effects in manatees occurred following weeks of exposure from several routes, the data suggest that the respiratory tract and hematopoietic systems might be affected, although to a lesser degree, following repeated exposure of humans to environmentally relevant airborne concentrations of brevetoxins. Immunohistochemical staining of tissues from these manatees indicated an accumulation of brevetoxins in tissue macrophages and lymphocytes, key players in humoral and cell-mediated immune responses, suggesting that the immune system also may be adversely affected upon repeated exposure. Recently rats were exposed to aerosols of crude $K$. brevis extract $4 \mathrm{hr} / \mathrm{day}$ for 1 and 4 wk that contained primarily brevetoxins 2 and 3 , as well as a newly discovered brevetoxin antagonist (Bourdelais et al., 2003). The only effect observed was a statistically significant suppression in antibody recognition by spleen cells after 1 and 4 wk of exposure. The effect occurred at both concentrations tested, and the extent of suppression was not dose dependent (Benson et al., 2003).

The purpose of this study was to extend our investigation of the adverse systemic health effects, exclusive of acute respiratory tract irritation, associated with brevetoxin inhalation by focusing on brevetoxin 3 (Figure 1), a major component of K. brevis extract. The brevetoxin 3 aerosol 
concentration was chosen to deposit similar amounts of brevetoxin in the respiratory tract as were deposited in the K. brevis extract studies (Benson et al., 2003). The concentration was 23 orders of magnitude higher total brevetoxin concentrations measured along red tide-affected Florida beaches (Backer et al, 2003;Pierce et al., 2003).

\section{METHODS AND STUDY DESIGN}

\section{Chemicals}

Brevetoxin 3 (Figure 1) was isolated and purified from K. brevis cultures at the Center for Marine Sciences, University of North Carolina, Wilmington, using established procedures (Baden et al., 1981). Zymosan was purchased from Sigma Chemical Company (St. Louis, MO). RPMI 1640 and fetal bovine serum were purchased from GIBCO (Grand Island, NY).

\section{Animals}

Male F344/CrlBr rats (6-7 wk old weighing 100 - 150 g) purchased from Charles River Laboratories (Wilmington, MA) were used. Rats were housed in polycarbonate cages with hardwood chip bedding. The animal rooms were maintained at $20-22^{\circ} \mathrm{C}$ with relative humidity at $20-50 \%$ and a 12-hr light cycle beginning at 0600. Rodent diet (Harlan Teklad, Madison, WI) and water were provided ad libitum, except during inhalation exposures. For the toxicity assessment, the rats were randomized by weight into dose groups and endpoint groups and identified by tail tattoo. All rats were conditioned to the nose-only inhalation restraint tubes before exposures began on three separate days, for 0.5 , one and two hr on days 1, 2 and 3, respectively.

\section{Inhalation Exposures}

Exposure System-The exposure system consisted of two (one brevetoxin, one vehicle control), 36-port cylindrical nose-only inhalation chambers (InTox Products, Edgewood, NM). Aerosols generated by nebulization (Hospitak, Inc., Farmingdale, NY) were dried and diluted with supply air to achieve the desired chamber aerosol concentrations. Total airflow through the chambers was $10 \mathrm{~L} / \mathrm{min}$. Chambers were operated at a slightly negative pressure with respect to the glove boxes in which they were enclosed. The brevetoxin 3 chamber was housed within a glovebox to minimize worker exposure. Temperatures were monitored continuously with an acceptable range of $18-22^{\circ} \mathrm{C}$. Chamber oxygen concentration was monitored with an action level at $\leq 18 \%$.

Aerosol Generation and Characterization-Stock solutions containing $0.5 \mathrm{mg}$ brevetoxin/mL were prepared in $100 \%$ ethanol. Generator solutions were prepared daily by diluting the stock solutions with $0.9 \%$ saline to achieve a final concentration of $0.15 \mathrm{mg}$ brevetoxin $3 / \mathrm{mL}$. The ratio of brevetoxin mass to total mass in the solutions was 0.023 . The target concentration of brevetoxin in the saline-based aerosol was $500 \mu \mathrm{g} / \mathrm{m}^{3}$.

Total aerosol concentrations in the exposure atmospheres were determined gravimetrically. Aerosol was collected from the breathing zone of the animals at a flow rate of $2 \mathrm{~L} / \mathrm{min}$ onto pre-weighed 25-mm Zefluor filters (SKC Gulf Coast, Houston, TX). Sequential half-hour filter samples were collected throughout each exposure. The stability of the total aerosol concentration during the exposure was monitored using a TSI DustTrak ${ }^{\mathrm{TM}}$ real-time aerosol monitor (TSI Industries, Shoreview, MN). The particle size distributions of the aerosols were determined using an eight-stage cascade impactor.

The brevetoxin aerosol concentration was calculated as $0.023 * \mathrm{mg}$ total aerosol $/ \mathrm{m}^{3}$. Brevetoxin 3 aerosol concentrations were confirmed by ELISA analysis (Naar et al., 2002) performed on a subset of filter samples (one per exposure day) extracted with acetone. To 
verify the stability of brevetoxin 3 during aerosolization, acetone filter extracts were dried and resuspended in methanol and water (50:50). Samples were injected onto a high-pressure liquid chromatograph (10ADVP, Shimadzu Company, Kyoto, Japan) equipped with a $75 \times 2-\mathrm{mm}$ analytical column (Aqua $3 \mu \mathrm{m}$, Phenomenex USA, Torrance, CA). Brevetoxin was eluted using a methanol-water mobile phase containing $1 \mathrm{mM}$ ammonium acetate. Eluant was directed into an electrospray mass spectrometer (API 365, Applied Biosystems, Foster City, CA). The mass spectrometer was monitored for ion pairs consisting of 897.590/725.404, indicative of brevetoxin 3 .

\section{Experimental Design}

Groups of 11 rats each were exposed for 5 consecutive days to brevetoxin 3 for $0.5 \mathrm{~h}$ (lowdose group) or $2 \mathrm{hr}$ (high-dose group). Control rats were sham exposed $2 \mathrm{hr} /$ day to aerosols generated by the nebulization of the alcohol/saline vehicle. All rats were observed for clinical signs of toxicity during and after each exposure. Toxicological endpoints for Group A rats (6 rats per exposure group) included: 1) terminal body and organ weights at necropsy, 2) gross and histopathological changes, 3) localization of brevetoxin 3 in tissues by immunohistochemcal staining, 4) evaluation of biochemical and cytological changes in bronchoalveolar lavage fluid as an indicator of pulmonary inflammation and cytotoxicity, and 5) alveolar macrophage activation. Group A rats were housed in metal metabolism cages with wire mesh floors after each exposure for collection of urine and feces for identification and quantitation of excretion and brevetoxin metabolites under a separate protocol. Group B rats (5 rats per dose group) were included evaluation of the effect of inhaling brevetoxin on systemic immunity.

In-Life Observations-All rats were observed for clinical signs of toxicity after each day's exposure.

Antibody-Forming Cell Response-The IgM antibody-forming cell (AFC) response to the T-cell dependent antigen, sheep red blood cells (SRBC), was assessed with a modified plaque-forming assay (Cunningham \& Szenberg, 1968). Tissue burden/immunology group rats $(\mathrm{n}=5)$ were immunized by tail vein injection of $250 \mu \mathrm{L}$ of a $15 \%$ suspension of SRBC in phosphate-buffered saline (Colorado Serum Company, Denver, CO). At 4 days post immunization (one day after the last inhalation exposure), the rats were euthanized by intraperitoneal injection of Euthasol ${ }^{\circledR}$. The portion of spleen to be used for the assay was placed in RPMI culture medium on ice. Single cell suspensions were prepared by pressing the spleens through a steel mesh. Cells were washed, red blood cells lysed, rewashed twice in complete RPMI culture medium, and then resuspended in complete RPMI to a final concentration of 1 $\times 10^{6}$ cells $/ \mathrm{mL}$. A mixture of lymphoid cells $(0.2 \mathrm{~mL} ; 200,000$ cells $), 20 \mu \mathrm{L}$ of guinea pig complement, and $20 \mu \mathrm{L}$ of SRBC suspension (15\% as described above) was incubated in a chamber made of two microscope slides sealed with paraffin. The chambers were incubated at $37^{\circ} \mathrm{C}$ for $45 \mathrm{~min}$ in a humidified $5 \% \mathrm{CO}_{2}$ atmosphere. The number of plaque-forming cells (PFC) was determined by light microscopy and reported as $\mathrm{PFC} / 10^{6}$ lymphoid cells.

Necropsy-Group A rats were sacrificed by intraperitoneal injection of Euthasol ${ }^{\circledR}$, and body weights were recorded. Each animal received a complete necropsy. Brain, lung, liver, kidneys, spleen, and thymus weights were recorded. To obtain bronchoalveolar lavage fluid for analysis, the left lung bronchus was temporarily clamped, and the right lobes were lavaged twice with $4 \mathrm{~mL}$ physiological saline. The fluid recovered from each lavage was placed in separate tubes (two tubes per rat). Following the lavage, the right bronchus was ligated. The left lobe was fixed by inflation via the trachea using 10\% neutral buffered formalin. Tissues fixed in 10\% neutral buffered formalin included representative organs from the digestive, nervous, endocrine, respiratory, cardiovascular, hematopoietic, and urogenital systems. 
Histopathology-Nose (not decalcified), brain, liver, lung, and spleen were embedded in paraffin, sectioned at 5 microns, and stained with hematoxylin and eosin for histopathology evaluation. Microscopic lesions, when present, were graded for severity. Additional sections of each tissue type were prepared on ProbeOn ${ }^{\mathrm{TM}}$ Plus microscope slides for immunohistochemical staining for brevetoxin (Bossart et al., 1998).

Lavage Fluid Processing-The volume of fluid recovered in the first lavage wash was recorded. Samples from each rat were centrifuged $\left(1,000 \mathrm{rpm}\right.$ for $10 \mathrm{~min}$ at approximately $5^{\circ}$ C) to sediment recovered cells. The supernatant from the first lavage was analyzed for lactate dehydrogenase (LDH) activity and total protein using a Monarch Chemistry System (Instrumentation Laboratories, Lexington, MA).

The cell pellets from both washes from each animal were pooled and counted manually using a hemocytometer. Differential counts of nucleated cells were made on cytocentrifuge preparations stained with Kwik ${ }^{\mathrm{TM}}$ Diff (Shandon, Inc., Pittsburgh, PA).

Alveolar Macrophage Activation-The state of activation of the macrophages recovered in lavage fluid was determined using a zymosan-stimulated chemiluminescence assay to measure $\mathrm{H}_{2} \mathrm{O}_{2}$ production (Hubbs et al., 2001). Macrophages were placed in 96-well microtiter dishes as $2 \times 10^{5}$ cells/well in HEPES-buffered Earle's solution. After $1 \mathrm{hr}$ incubation at $37^{\circ} \mathrm{C}$ to permit cell attachment, wells received rat serum-opsonized zymosan or buffer only (to assess spontaneous $\mathrm{H}_{2} \mathrm{O}_{2}$ formation). Following the addition of $0.25 \mathrm{mg} / \mathrm{mL}$ horseradish peroxidase: $0.5 \mathrm{mg} / \mathrm{mL}$ luminol, luminescence was monitored real-time at 4-min intervals for 36 min. Luminescence units were summed over the 36-min period for each sample. Results are expressed as luminescence units $/ 2 \times 10^{5}$ cells.

Statistical Analyses-Means, standard deviations, and standard errors for experimental parameters other than body and organ weights were calculated using Microsoft Excel software. One-way analysis of variance was used to test if there was a statistically significant trend in the data (GraphPad Software, Inc., San Diego, CA). If group variances were not significantly different, the ANOVA were performed with a Dunnett's post test to assess differences among exposure groups. If group variances were significantly different, the Kruskal-Wallis test was used with Tukey's post test for multiple comparisons. Group mean body weight and organ weight data were tested for statistical significance using Path-Tox ${ }^{\circledR}$ software. Bartlett's test was used to establish the homogeneity of the data. If the data were homogeneous, significance was evaluated using a modified Dunnett's test. If data were non-homogeneous, a modified ttest was used. For all parameters, the criterion for significance was set at $\mathrm{p}<0.05$.

\section{RESULTS}

\section{Exposure Atmosphere}

The characteristics of the exposure atmosphere are summarized in Table 1. The mean brevetoxin aerosol exposure concentrations for the low dose $(0.5 \mathrm{hr})$ and high dose $(2 \mathrm{hr})$ groups were within $2 \%$ of each other. Mass spectral analysis confirmed the presence of brevetoxin 3 in the aerosol. The particle size distribution in the in the control chamber was $0.91 \mu \mathrm{m}$ mass median aerodynamic diameter (MMAD) with a geometric standard deviation $\left(\sigma_{\mathrm{g}}\right)$ of 2.13 . The MMAD of the brevetoxin-containing aerosol was $1.46-\mu \mathrm{m}$ with a $\sigma_{\mathrm{g}}$ of 1.9. Both aerosols were highly respirable.

\section{General Toxicity}

Other than transient lethargy among some high-dose rats, no clinical signs of toxicity were observed. There was no sign of respiratory or mucous membrane irritation during or 
immediately after the exposures. The cholinergic effects associated with neurotoxic shellfish poisoning and alterations in balance and gait were also absent.

The mean body weight of all rats $(n=33)$ before the exposures began was $308.2 \pm 1.78 \mathrm{~g}$. Body weights of Group A and B rats at sacrifice are summarized in Table 2. All rats, including controls, lost weight during the 5-day exposure period, with losses being greater in Group A than Group B animals. Some weight loss could be attributed with the nose-only exposures, despite conditioning of the animals to the restraint tubes. Lower overall weights of Group A rats compared to Group B rats is likely due to differences in housing conditions within the same room within the vivarium (metal metabolism cages versus shoebox cages). Brevetoxin inhalation had no marked effect on body weights of Group A rats. However, mean body weight of Group B rats exposed $2 \mathrm{hr} /$ day to brevetoxin 3 were significantly below that of the Group B controls.

\section{Gross Pathology and Terminal Body and Organ Weights}

No lesions were observed at necropsy in control or brevetoxin 3-exposed rats. Brevetoxin 3 inhalation for 5 days had no apparent effect on organ weights (data not shown).

\section{Histopathology and Cellular Localization of Brevetoxin in Tissues}

There were no microscopic lesions in the nose, brain, lung, liver, or spleen of control or brevetoxin-exposed rats. Macrophages in bronchus-associated lymphoid tissues from highdose rats stained positively for brevetoxin (Figure 2). Macrophages, but not lymphocytes, stained positively for brevetoxin in spleens of high-dose rats (Figure 3). There were no brevetoxin-positive cells in the nasal mucosa, brain, or liver.

\section{Lavage Fluid Parameters}

Lactate dehydrogenase activity in BALF from control rats was $193 \pm 28.6 \mathrm{mIU} /$ right lung (mean $\pm \mathrm{SD}, \mathrm{n}=5$ ); protein concentration was $0.58 \pm 0.05 \mathrm{mg} /$ right lung. These parameters were not affected by brevetoxin inhalation (data not shown). Numbers of nucleated cells recovered in lavage fluid were significantly decreased in high-dose but not low dose rats, compared to controls (Table 3). Nucleated cells recovered in lavage fluid were $\geq 98 \%$ macrophages for control and brevetoxin-exposed animals. A small \% of macrophages in lavage fluid from low- and high-dose rats were brevetoxin-positive.

Control rat number $\mathrm{C} 602$ had high baseline $\mathrm{H}_{2} \mathrm{O}_{2}$ production (almost two standard deviations from the mean) and high $\mathrm{H}_{2} \mathrm{O}_{2}$ production upon zymosan administration. There were no biochemical or cellular differences in the lavage fluid or lung histopathology in this animal to suggest a reason for macrophage activation. Therefore, the statistical analysis of the macrophage activation, as indicated by $\mathrm{H}_{2} \mathrm{O}_{2}$ production, was analyzed with and without the value for rat $\mathrm{C} 602$. Baseline hydrogen peroxide production among high-dose rats was significantly increased above control values with and without inclusion of rat C602 (Table 3). A significant trend toward increased $\mathrm{H}_{2} \mathrm{O}_{2}$ production with the addition of zymosan was observed only when $\mathrm{C} 602$ data were excluded from the analysis, and only high-dose rats showed significantly increased $\mathrm{H}_{2} \mathrm{O}_{2}$ production above control values. When $\mathrm{C} 602$ data were excluded, net $\mathrm{H}_{2} \mathrm{O}_{2}$ production (zymosan stimulated, baseline) was significantly increased for both low- and high-dose groups compared to control.

\section{Antibody Forming Cell Response}

Repeated brevetoxin 3 inhalation had no marked effect on spleen weights or numbers of lymphoid cells isolated from spleens (Table 4). Numbers of PFC were depressed by more than 
$70 \%$ in spleen cells following brevetoxin 3 inhalation. The magnitude of suppression was similar in the low- and high-dose groups.

\section{DISCUSSION}

Brevetoxins are potent neurotoxins with documented toxicity in humans (neurotoxic shellfish poisoning), marine mammals, birds, and fish (Bossart et al, 1998; Kreuder et al, 2002; Kirkpatrick et al, 2003). The purpose of this pilot study was to begin investigation of toxic effects and dose-response relationships resulting from repeated inhalation of wellcharacterized aerosols of a representative component of $K$. brevis, brevetoxin 3 .

The sodium chloride-based brevetoxin aerosol produced for this study was respirable and polydisperse. The mean gravimetric concentration achieved, $532 \mu \mathrm{g} / \mathrm{m}^{3}$ was within $10 \%$ the targeted $500 \mu \mathrm{g} / \mathrm{m}^{3}$. The concentration determined by ELISA is somewhat higher than calculated gravimetrically. However, in studies where brevetoxin was spiked in known amounts on filters, ELISA results were consistently 15-20\% higher than spiked values. Taking this into consideration, ELISA supported the calculated brevetoxin 3 aerosol concentrations in this experiment.

Respiratory tract deposition of brevetoxin in the rat can be calculated as follows: $\mu \mathrm{g}$ deposited $=\mu \mathrm{g} / \mathrm{L}$ aerosol concentration $*$ minute volume $(\mathrm{L} / \mathrm{min}) *$ exposure duration $(\mathrm{min}) *$ deposition fraction. Assuming a minute volume of $0.25 \mathrm{~mL} / \mathrm{min}$ for rats, and total respiratory tract deposition of approximately 0.6 (for $2 \mu \mathrm{m}$ particles, Schlesinger, 1989), total amount of brevetoxin deposited in the respiratory tract per day was 2.3 and $9 \mu \mathrm{g}(8.3$ and $33 \mu \mathrm{g} / \mathrm{kg})$ for the low- and high-dose rats, respectively.

Rats observed during and immediately after exposure did not show obvious signs of mucous membrane irritation. There were no visible changes in respiratory frequency or behavioral changes indicative of respiratory tract irritation, but direct measurements of respiratory frequency or irritation were not made to confirm the absence of effect. The absence of at least mucous membrane irritation at concentrations orders of magnitude greater than those measured along red tide affected beaches suggest the rat may not be an appropriate model for assessing this endpoint. Abraham and co-workers (2003) have demonstrated that sheep are very sensitive to the bronchocontrictive effects of inhaled brevetoxins, and therefore are a better model than the rat for studying this brevetoxin-induced changes in airway resistance.

Immunohistochemically positive lymphoid macrophages confirmed brevetoxin deposition in the lung. Brevetoxin-positive macrophages in spleens indicated systemic distribution as was expected based on studies of the uptake and distribution of radiolabled brevetoxin 3 in rats (Benson et al, 1999, Cattet and Geraci, 1993; Poli et al, 1990. Mononuclear cell but not epithelial cell staining in brevetoxin-exposed rats is consistent with the pattern of staining among manatees dying from extreme brevetoxin exposure during Florida red tides (Bossart et al., 1998). However, unlike the manatees, mononuclear cells in the liver and brain of exposed rats in this study did not stain positively for brevetoxin. These differences in staining pattern may be attributable to the influx of inflammatory cells into many tissues, including brain and liver, nose, and lung of the manatees (Bossart et al, 1998), but not rats in this study.

In contrast to large extensive macrophages and lymphocytes infiltration in tissues of manatees undergoing extreme exposure K. brevis during the 1996 epizootic, no inflammatory responses were observed in the respiratory tract or any tissue of brevetoxin-exposed rats. The concentrations of brevetoxin in the waters during the 1996 epizootic were not determined. It is only known that the manatees were exposed for days to weeks by ingestion, inhalation, and dermal absorption (Bossart et al, 1998). It is likely that differences in response between 
manatees and rats are due to differences in brevetoxin dose and duration of exposure. No data are available on species differences to the sensitivity of manatees and rodents to brevetoxins.

Alveolar macrophages from high-dose rats had increased baseline $\mathrm{H}_{2} \mathrm{O}_{2}$ production compared to control rats (with or without inclusion of rat $\mathrm{C} 602$ from the analysis). Therefore, brevetoxin inhalation activated these cells. Brevetoxin exposure did not reduce macrophage response to zymosan stimulation compared to control cells. Therefore, alveolar macrophages in brevetoxin-exposed rats at least maintained, and may have had some enhanced, ability to respond to particle challenge by increasing production of reactive oxygen species.

Antibody production against SRBC reflects immune function, including that mediated by macrophages, T-cells, and B-cells (Luster et al, 1988). Measuring the numbers of PFCs against SRBC splenocytes after sensitization with SRBC is a method commonly used for assessing the in vivo potential of splenic antibody production (Luster et al, 1988). A major finding of this study was the significant reduction in spleen PFC response among low- and high-dose animals after only one week of exposure to brevetoxin. Significant reduction (76\%) at the low dose ( 0.5 -hr exposure to $500 \mu \mathrm{g} / \mathrm{m}^{3} ; 8.3 \mu \mathrm{g} / \mathrm{kg} / \mathrm{day}$ ) suggests the effect may occur at lower airborne concentrations. Earlier studies showed significant reductions in the numbers of PFCs in Sprague-Dawley rats exposed to a crude $K$. brevis extract for 1 and 4 wk (Benson et al., 2003). The results of this study confirm that finding and indicate that the effect can be produced by inhalation exposure to a pure brevetoxin in the absence any overt toxicity to the spleen (no changes in weight, histopathological changes, or numbers of isolated splenocytes). By comparison with other toxicants, inhalation exposure of $\mathrm{CD}$ rats to the pesticide carbaryl at $334 \mathrm{mg} / \mathrm{m}^{3}, 6 \mathrm{hr} /$ day 5 days/week for 2 weeks resulted in significant decreases of 33,57 and $22 \%$ in spleen cell number, PFC/spleen, and thymus weight, respectively (Ladics et al, 1994). Oral doses of the mycotoxin, fumonisin $\mathrm{B}_{1}$ of $25 \mathrm{mg} / \mathrm{kg} / \mathrm{day}$ for 14 days reduced PFCs by only $21 \%$ (Tryphonas et al., 1997). Oral doses $(600 \mathrm{mg} / \mathrm{kg} / \mathrm{day}$ for $1 \mathrm{wk})$ of the triazine herbicide simazine reduced numbers of splenic PFCs in mice by approximately 50\% (Kim et al., 2003).

Cathepsins are proteolytic enzymes involved in antigen processing and presentation (Honey $\&$ Rudensky, 2003). Inhibition of these enzymes suppresses responses to exogenous antigens, switches T-cell responses of $\mathrm{CD}^{+}$cells, and reduces production of $\operatorname{IgE}$ and $\operatorname{IgG}$ (Katunuma et al., 2003). Brevetoxin effectively inhibits the proteolytic activity of cathepsin L (Sudarsanam et al., 1992). Cathepsin inhibition may represent the mechanism for the suppression of the spleen antibody forming cell response observed in this study. Further work is planned to investigate this possibility.

\section{Acknowledgments}

This research funded under NIH P01-ES10594ZES. The authors are grateful for the excellent technical assistance of Deborah Meyer, Carolyn Elliott, Amber Dison, Colleen Santistevan, Sarah Durr, Dean Kracko, and Brad Tibbetts.

\section{REFERENCES}

Abraham WM, Ahmed A, Bourdelais AJ, Baden DG. Pathophysiologic Airway Responses to Inhaled Red Tide Brevetoxin in Allergic Sheep. The Toxicologist 2003;72:115.

Asai S, Krzanowski JJ, Anderson WH, Martin DF, Polson JB, Lockey RF, Bukantz SC, Szentivanyi A. Effects of the toxin of red tide, Ptychodiscus brevis, on canine tracheal smooth muscle: a possible new asthma-triggering mechanism. J. Allergy Clin Immunol 1982;69:418-428. [PubMed: 7200498]

Backer LC, Fleming LE, Rowan A, Cheng Y-S, Benson J, Pierce RH, Zaias J, Bean J, Bossart GD, Johnson D, Quimbo R, Baden DG. Recreational exposure to aerosolized brevetoxins during Florida red tide events. Harmful Algae 2003;2:19-28. [PubMed: 19081765]

Baden DG, Mende JJ, Lichter W, Wellham L. Crystallization and toxicology of T34: a major toxin from Florida's red tide organism (Ptychodiscus brevis). Toxicon 1981;19:455-462. [PubMed: 7199210] 
Baden DG. Brevetoxins: unique polyether dinoflagellate toxins. FASEB J 1989;3:1807-1817. [PubMed: 2565840]

Benson JM, Tischler DL, Baden DG. Uptake, tissue distribution, and excretion of brevetoxin 3 administered to rats by intratracheal instillation. J. Toxicol. Environ. Health A 1999;57:345-355. [PubMed: 10405188]

Benson, JM.; Hahn, FF.; Tibbetts, BM.; Bowen, LE.; March, TH.; Langley, RJ.; Murray, TF.; Bourdelais, AJ.; Naar, J.; Baden, DG. Florida red tide: inhalation toxicity of Karenia brevis extract in rats. In: Steidinger, KA.; Landsberg, JH.; Tomas, CR.; Vargo, GA., editors. Harmful algae 2002, Proceedings of the Xth International Conference on Harmful Algae; Florida Fish and Wildlife Conservation Commission and Intergovernmental Oceanographic Commission of UNESCO; 2003.

Bossart GD, Baden DG, Ewing RY, Roberts B, Write SD. Brevetoxicosis in manatees (Trichechus manatus latirostris) from the 1996 epizootic: gross, histologic, and immunohistochemical features. Toxicol. Pathol 1998;26:276-282. [PubMed: 9547868]

Bourdelais, AJ.; Campbell, S.; Benson, J.; Abraham, WM.; Naar, J.; Kubanek, J.; Wright, JLC.; Baden, DG. Florida's red tide dinoflagellate Karina brevis may modulate its potency by producing a nontoxic competitive antagonist. In: Steidinger, KA.; Landsberg, JH.; Tomas, CR.; Vargo, GA., editors. Harmful Algae 2002, Proceedings of the Xth International conference on Harmful Algae; Florida Fish and Wildlife Conservation Commission and Intergovernmental Oceanographic Commission of UNESCO; 2003.

Cattet M, Geraci JR. Distribution and elimination of ingested PbTx (PbTx-3) in rats. Toxicon 1993;31:1483-1486. [PubMed: 8310449]

Cunningham AJ, Szenberg A. Further improvements in the plaque technique for detecting single antibody-forming cells. Immunology 1968;14:599-600. [PubMed: 5653817]

Honey K, Rudensky AY. Lysosomal cysteine proteases regulate antigen presentation. Nat. Rev. Immunol 2003;3:472-482. [PubMed: 12776207]

Hubbs AF, Minhas NS, Jones W, Greskevitch M, Battelli LA, Porter DW, Goldsmith WT, Frazer D, Landsittel DP, Ma JY, Barger M, Hill K, Schwegler-Berry D, Robinson VA, Castranova V. Comparative pulmonary toxicity of 6 abrasive blasting agents. Toxicol. Sci 2001;61:135-143. [PubMed: 11294984]

Katunuma N, Matsunaga Y, Himeno K, Hayashi Y. Insights into the roles of cathepsins in antigen processing and presentation revealed by specific inhibitors. Biol. Chem 2003;384:883-890. [PubMed: 12887055]

Kim KR, Son EW, Hee-Um S, Kim BO, Rhee DK, Pyo S. Immune alterations in mice exposed to the herbicide simiazine. J. Toxicol. Environ. Health A 2003;66:1159-1173. [PubMed: 12791541]

Kirkpatrick B, Fleming LE, Squicciarini D, Backer LC, Clark R, Abraham W, Benson J, Cheng YS, Johnson D, Pierce R, Zaias J, Bossart G, Baden DG. Literature review of Florida red tide: implications for human health effects. Harmful Algae 2003;3:99-115.

Kreuder C, Mazet JA, Bossart GD, Carpente TE, Holyoak M, Elie MS, Wright SD. Clinopathologic features of suspected brevetoxicosis in double-crested cormorants (Phalacrocorax auritus) along the Florida Gulf Coast. J Zoo Wildl Med 2002;33:8-15. [PubMed: 12216798]

Ladics GS, Smith C, Heaps K, Loveless SE. Evaluation of the humoral immune response of CD rats following a 2-week exposure to the pesticide carbaryl by the oral, dermal, or inhalation routes. J. Toxicol. Environ. Health 1994;42:143-156. [PubMed: 8207751]

Luster MI, Munson AE, Thomas PT, Lauer LD, Germolec DR, Rosenthal Gj, Deans JH. Fundam. Appl. Toxocol 1988;10:2-19.

Naar J, Bourdelais A, Tomas C, Kubanek J, Whitney PL, Flewelling L, Steidinger K, Lancaster J, Baden DG. A competitive ELISA to detect brevetoxins from Karenia brevis (formerly Gymnodinium breve) in seawater, shellfish, and mammalian body fluid. Environ. Health Perspect 2002;110:179-185. [PubMed: 11836147]

Pierce RH, Henry MS, Blum PC, Lyons J, Cheng YS, Yazzie D, Zhou Y. Brevetoxin concentrations in marine aerosol: human exposure levels during a Karenia brevis harmful algal bloom. Bull. Environ. Contam. Toxicol 2003;70:161-165. [PubMed: 12478439]

Poli MA, Templeton CB, Thompson WL, Hewetson JF. Distribution and elimination of brevetoxin PbTx-3 in rats. Toxicon 1990;28:903-910. [PubMed: 2080516] 
Schlesinger, RB. Deposition and clearance of inhaled particles. In: McClellan, RO.; Henderson, RF., editors. Concepts in Inhalation Toxicology. New York: Hemisphere Publishing Co; 1989. p. 163-192.

Sudarsanam S, Virca GD, March CJ, Srinivasan S. An approach to computer-aided inhibitor design: application to cathepsin L. J. Comput. Aided Mol. Res 1992;6:223-233.

Tryphonas H, Bondy G, Miller JD, Lacroix F, Hodgen M, Mcguire P, Fernie S, Miller D, Hayward S. Effects of fumonisin $\mathrm{B}_{1}$ on the immune system of Sprague-Dawley rats following a 14-day oral (gavage) exposure. Fundam. Appl. Toxicol 1997;39:53-59. [PubMed: 9325027]

Van Dolah FM. Marine algal toxins: origins, health effects, and their increased occurrence. Environ. Health Perspect 2000;108:133-141. [PubMed: 10698729] 


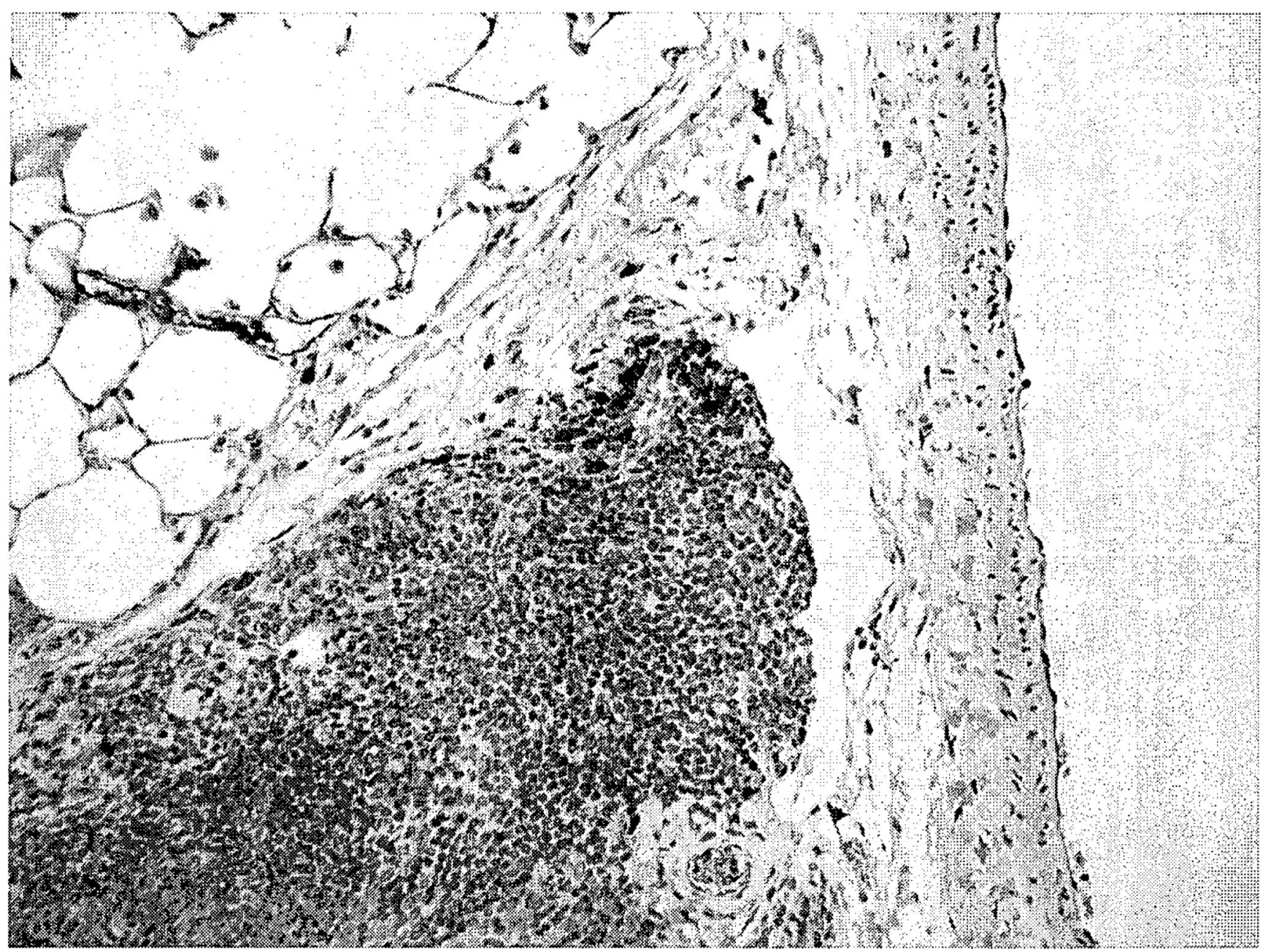

FIGURE 1.

The structure of brevetoxin 3 . 


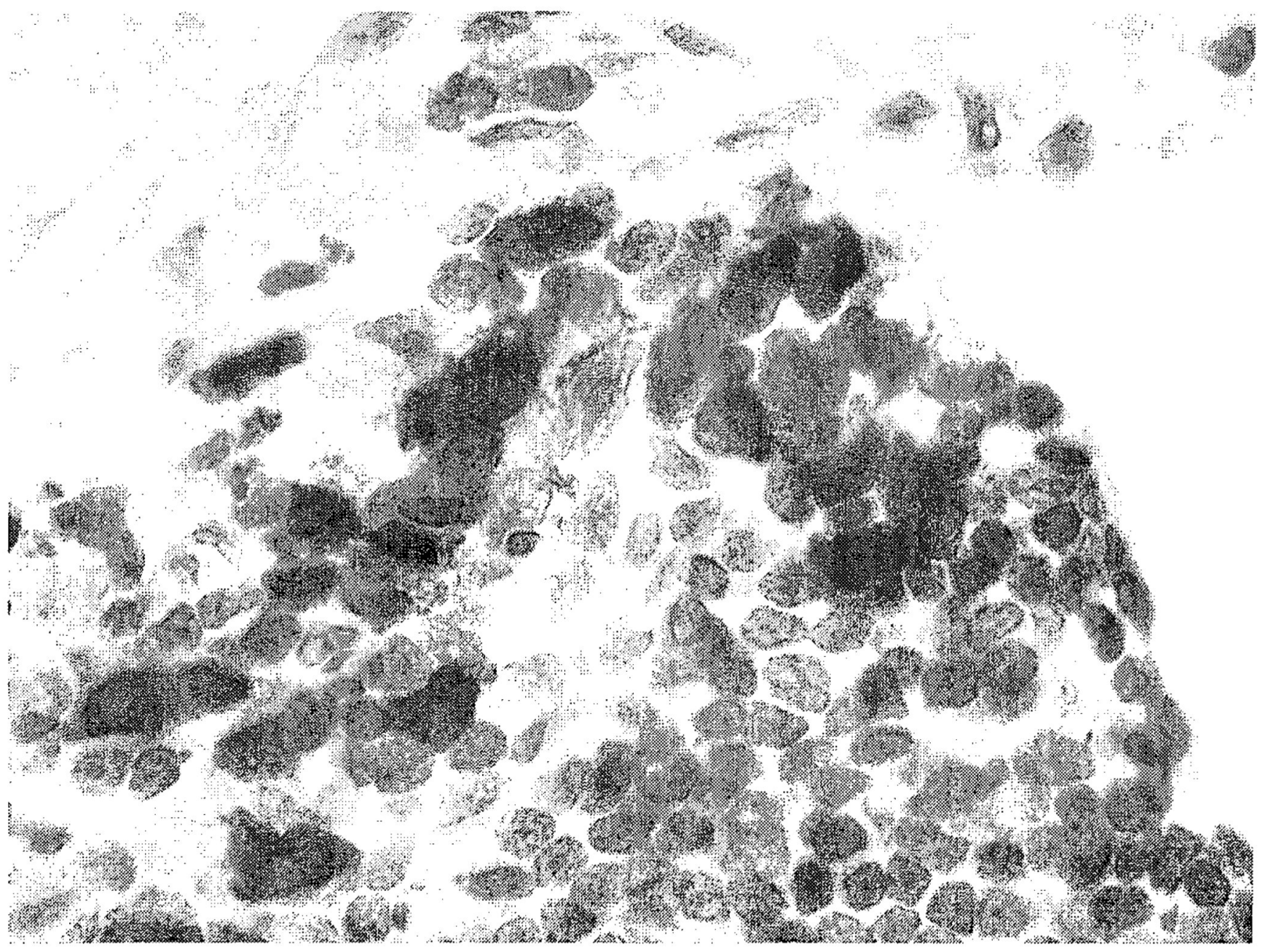

FIGURE 2.

Photomicrograph of a high-dose brevetoxin-exposed rat lung. Small numbers of peribronchiolar lymphoid tissue macrophages are brevetoxin positive. Avidin-peroxidasebiotin method, hematoxylin counterstain, 400X. 


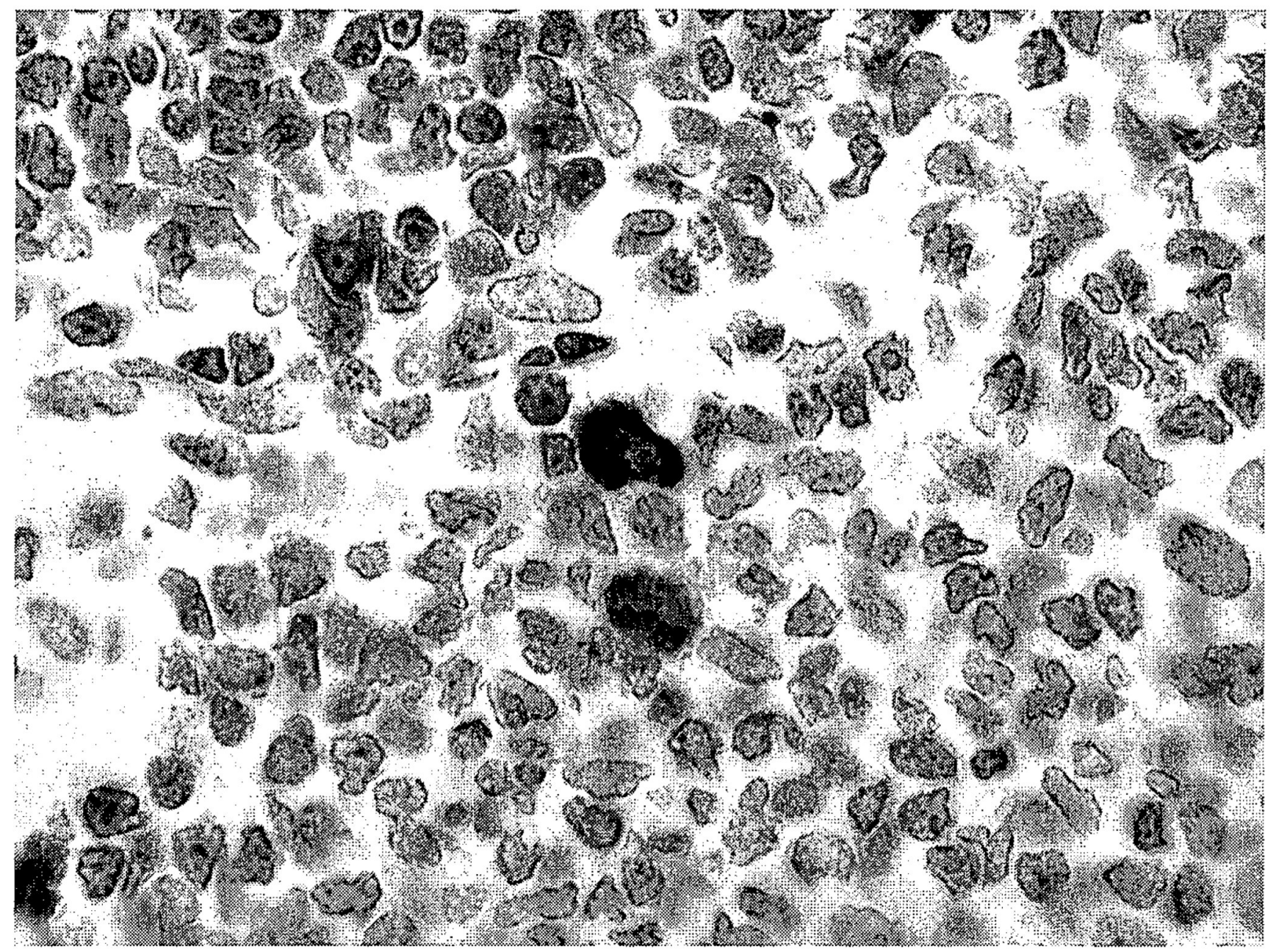

FIGURE 3.

Photomicrograph of a high-dose brevetoxin-exposed rat spleen. Small numbers of macrophages are brevetoxin positive. Avidin-peroxidase-biotin method, hematoxylin counterstain, 400X. 


\section{TABLE 1}

Exposure Atmosphere Characteristics

\begin{tabular}{|c|c|c|c|}
\hline Exposure Group & $\begin{array}{l}\text { Total Aerosol mg/m } \mathrm{m}^{3} \\
a\end{array}$ & $\begin{array}{l}\text { Calculated } \\
\text { Brevetoxin } \mu \mathrm{g} / \mathrm{m}^{3 a, b}\end{array}$ & $\begin{array}{l}\text { Brevetoxin } \mu \mathrm{g} / \mathrm{m}^{3} \text { by } \\
\text { ELISA }^{c}\end{array}$ \\
\hline Control & $21.7 \pm 2.5$ & NA & NA \\
\hline Low Brevetoxin 3 & $23.1 \pm 0.81$ & $542 \pm 32$ & $773 \pm 108$ \\
\hline High Brevetoxin 3 & $23.1 \pm 0.54$ & $532 \pm 12$ & \\
\hline Mean $\pm S D ; n=5$ & & & \\
\hline
\end{tabular}


TABLE 2

Effect of Brevetoxin Inhalation on Terminal Body Weight ${ }^{a}$

\begin{tabular}{lcl}
\hline & & Body Weight \\
\cline { 2 - 3 } Exposure Group & Group A $(\mathbf{n}=\mathbf{6})$ & Group B (n = 5) \\
\hline Control & $269 \pm 3.5$ & $282 \pm 11$ \\
Low Brevetoxin 3 & $269 \pm 9.9$ & $286 \pm 7.2$ \\
High Brevetoxin 3 & $270 \pm 5.3$ & $263 \pm 5.5^{b}$ \\
\hline
\end{tabular}

${ }^{a}$ Results are mean $\pm \mathrm{SD}$ of the number of values indicated in parentheses except for Group A controls, where $\mathrm{n}=5$.

${ }^{b}$ Mean significantly different from control, $\mathrm{p} \leq 0.05$ 


\section{TABLE 3}

Effect of Brevetoxin Inhalation on Numbers of Lavage Cells and Macrophage Activation

\begin{tabular}{lcccc}
\hline & $\begin{array}{c}\text { Numbers of } \\
\text { Nucleated } \\
\text { cells in } \\
\text { Lavage Fluid } \\
\left(\times \mathbf{1 0}^{\mathbf{6}}\right)\end{array}$ & Baseline & $\begin{array}{c}\text { Zymosan- } \\
\text { Stimulated }\end{array}$ & Net Stimulation \\
\hline Exposure Group & $2.89 \pm 0.57$ & $0.62 \pm 0.32$ & $4.7 \pm 2.9$ & $4.1 \pm 2.6$ \\
Lowtrol & $2.69 \pm 0.53$ & $(0.48 \pm 0.05)^{a}$ & $(3.5 \pm 1.5)^{a}$ & $(3.04 \pm 1.4)^{a}$ \\
High Brevetoxin 3 & $0.58 \pm 0.10$ & $8.3 \pm 4.0$ & $8.2 \pm 3.9^{b}$ \\
\hline
\end{tabular}

${ }^{a}$ Mean and standard deviation when data for rat C602 were excluded from the analyses.

${ }^{b}$ Significantly different from control using Kruskal-Wallis analysis of variance with Tukey's post test for multiple comparisons (p $\leq 0.05$ )

${ }^{c}$ Significantly different from control when data for rat C602 were excluded from the analyses; analysis of variance, Dunnett's post test for multiple comparisons $(\mathrm{p} \leq 0.05)$. 
TABLE 4

Effect of Brevetoxin 3 Inhalation on Numbers of Antibody Forming Cells in Spleen ${ }^{a}$

\begin{tabular}{lccr}
\hline Exposure Group & Spleen Weight $(\mathbf{g})$ & $\begin{array}{c}\text { Number Isolated } \\
\text { Lymphocytes/g } \\
\text { Spleen }\left(\mathbf{1 0}^{\mathbf{6}}\right)\end{array}$ & $\begin{array}{r}\text { PFC/100,000 } \\
\text { Lymphocytes }\end{array}$ \\
\hline Control & $0.60 \pm 0.04$ & $385 \pm 87$ & $1424 \pm 261$ \\
Low Brevetoxin 3 & $0.65 \pm 0.03$ & $386 \pm 36$ & $336 \pm 161^{b}$ \\
High Brevetoxin 3 & $0.61 \pm 0.06$ & $363 \pm 64$ & $400 \pm 198^{b}$ \\
\hline
\end{tabular}

${ }^{a}$ Results are the mean $\pm \mathrm{SD}$ of five values.

${ }^{b}$ Mean is significantly different from control, analysis of variance with Dunnett's post test $(\mathrm{p} \leq 0.05)$. 